\title{
Bridging Systems, Building a Coalition, and Centering Students: A Collaborative Multi-Campus Approach to Orientation in the Time of COVID-19
}

\author{
Katie Motycki, The Pennsylvania State University \\ Daniel W. Murphy, The Pennsylvania State University
}

This manuscript tells the story of how a multi-campus, public, Research I institution in the mid-Atlantic region pivoted from in-person orientation to a virtual orientation during the COVID-19 pandemic. We share how our university came together to offer a virtual orientation for 20 undergraduate campuses and 17,000 students in less than 100 days, review lessons learned, and offer insight into how this unusual year will influence planning for future orientation programs.

Keywords: virtual orientation, multi-campus, undergraduate orientation, COVID-19 response, collaboration, working teams

This manuscript outlines the experience at a multi-campus, public, Research I institution in the midAtlantic region. The university includes 20 four-year undergraduate campuses across the Commonwealth. All university courses are equivalent across all campuses, and students often move from campus to campus during their undergraduate careers. New student orientation (NSO) is a required activity for all first-year admits and is strongly recommended for transfer admits at every campus. NSO planners at each undergraduate campus and in each academic college at the flagship campus work in conjunction with a central office that coordinates onboarding activities for students (hereafter referred to as "the Orientation Office"). Together the NSO planners, the Orientation Office, and more than 150 additional faculty and staff engaged in orientation and transition programming across the university make up the Student Orientation and Transition Network.

This story starts on Wednesday, March 4, 2020. This is the day our director was called into one of the university's first COVID-19 response meetings. From there, the story accelerates at an exhausting speed. From March to August 2020, we created a virtual orientation experience for new students at all campuses and designed and implemented the first-ever extended orientation at our flagship campus. We share how we bridged systems, built a coalition of partners, and centered students in planning for virtual orientation in this paper. We begin with some context about new student orientation at our university.

\section{Background}

In non-pandemic times, the Orientation Office facilitates the first three steps of NSO for incoming students at each campus and academic college: (a) required placement testing, (b) reservations for NSO, and (c) the NSO task list. Each campus, using orientation curriculum and programming resources by the Orientation Office, then designs campus-based NSO programs reflecting the unique needs, characteristics, culture, resources, and 
people of each campus. For all new students at the flagship campus, the Orientation Office coordinates a twoday overnight required NSO experience. These students are admitted directly to one of 13 enrollment units or academic colleges. The Orientation Office provides leadership for and implements campus-wide programming and message delivery while working closely with NSO planners in each academic college to deliver a meeting and support the initial advising appointment.

Our standard orientation cycle follows an established pattern. Students gain access to the first steps of the orientation process beginning March 1 if they have accepted their offer of admission. Step 1 includes completing the required math placement exam and signing up to participate in the summer bridge program, which typically serves about 1,300 new students at the flagship campus each summer. On or near April 1, we make orientation dates available for students and their families to make a reservation.

The positioning of the Orientation Office in the university structure helps make this possible. When the office was created in 2012, a dual reporting structure was established. The Orientation Office reports to both Student Affairs and Undergraduate Education, which includes the Enrollment Management operations.

\section{COVID-19 Action Teams}

In early March 2020, the provost announced 12 action teams that would help steer the university's response to COVID-19. Two of these action teams were combined and asked to address "enrollment management and semester/summer course delivery interruption." This team has been meeting weekly ever since to discuss and navigate issues and challenges related to both of these areas for the university.

As part of that action team's work, several sub-groups were identified to address specific areas of the overall charge. Out of a need for efficiency, they were assigned letters - Team A, Team B, and so on. Team F was charged with acclimating and orienting new first-year, transfer, and graduate students to the university. This team would ensure continuity between admission to the university and enrollment through a series of deliberate engagements and communications with students (see Appendix A).

The director for the Orientation Office and a peer director in Global Programs were named co-chairs of Team F on March 9. Joining them were academic advisors from many of the campuses and academic colleges, staff from the online world campus, undergraduate admissions, orientation, the graduate school, and global programs. Team F did not waste any time and quickly got to work making contingency plans for orientation programs, knowing that an in-person experience during a global pandemic would be unlikely. While little was known about the science of COVID-19 at the time, the inequitable impacts of the virus were already being felt around the country. Even if the science would allow us to host an in-person program, we knew that many new students and families would not be able to participate because of quarantine or isolation, job loss, family loss, the costs associated with travel, or travel restrictions themselves. On March 18, Team F's contingency plan received the green light. It would not be publicly announced for another five weeks. Still, we received permission to plan a university-wide virtual orientation program to serve every first-year and transfer admit at each of the 20 undergraduate campuses.

\section{Planning and Executing Virtual Orientation}

This contingency plan outlined how the university could continue to meet the mission-critical elements of orientation programs, maintain equity in access to services and experiences for new students and their support networks, and maintain a competitive yield. In short, we proposed a virtual orientation program that would require students to attend a live-stream university Welcome, meet with other new students in a small group 
facilitated by an orientation leader, complete a campus or college-specific Canvas (the learning management system) course, and meet one-on-one with an academic advisor. Additionally, we would offer a series of optional activities that included virtual registration labs, game nights, coffee hours, and more. We facilitated this for each student through an online task list, supported by a series of emails.

\section{Using Existing Systems and Tools}

To support virtual orientation, we leveraged already existing systems and programs at the university. We already knew that students spend a lot of time in Canvas, and because of this, it made sense to host asynchronous orientation content on this platform. But first, we had to figure out how to give students access to it. We quickly learned of a circular error: Students are not activated in Canvas until they schedule their first class, but they do not schedule classes until they attend orientation. Thanks to the IT team's hard work, we could activate students in Canvas in advance of orientation.

Team F developed a set of eight core modules for each Canvas section. Each undergraduate campus and academic college also created content unique to their context. Designing the core modules was challenging. We had to find the right balance in messaging to meet the needs of each of the campuses: residential, commuter, urban, rural, small, mid-sized, and large alike. After creating the content, we partnered with a team of instructional designers to build the content in Canvas and include quizzes throughout to help us assess what students were learning.

Starfish serves a variety of student success initiatives and data tracking functions, and it is also how current students schedule an appointment with their academic advisor. We created new orientation services within Starfish that allowed orientation advisors to reserve space in their calendars for new students. We also connected new students to advisors based on their academic goals or intended majors. Starfish allowed academic advisors to manage their calendars throughout the summer and gave students the flexibility to schedule an appointment when it was convenient for them. The two met via Zoom, and we used a Starfish attendance record to mark that a student had completed the virtual orientation.

We developed plans to allow orientation leaders to host additional programming to introduce new students to other new students, play online games, or participate in get-to-know-you activities. We even found a way to make sure we could deliver our interactive musical theatre experience to a virtual audience.

We used our orientation reservation system (VisualZen) to help students move through the entire experience. None of the university's systems could talk to each other, so we had to retrofit the reservation system to help students navigate from one system to the other.

\section{Identifying Working Teams}

The plan was ambitious, and it became clear that Team F could not do this alone. After all, we had just 75 days until students arrived for orientation. If the program needed to pivot, it needed to pivot quickly. Team $\mathrm{F}$ identified 10 different working teams (see Appendix B) and made a university-wide call for staff and faculty who would like to help our efforts. It is safe to say that we were positively overwhelmed with the response. Our working teams grew to include more than 100 staff from 17 of our campuses.

Those staff members rose to the occasion and helped to give structure to the virtual orientation program. Team F served as the integration team-giving approvals, making tough decisions, and keeping the working teams focused when things got too creative or ambitious. One of our favorite sayings in spring 2020 was, "The only tool in our toolbox is a hammer." There were great ideas, but we were short on time to make each of them work. 
On April 23, the university made a public announcement stating that all NSO activities would be virtual in summer 2020. We opened reservations on Friday, April 24, and received 3,000 NSO reservations in four hours. The feeling that day was one of hope: we gave new students something to look forward to. By this time, senior years of high school had been upended, and classes moved to virtual spaces. Spring sports were unplayed, proms canceled, and graduations delayed, but on that day, new students could look forward to the start of their college careers.

Now that the plan was public, we had to make it a reality. While progress adjusting systems and developing online content was well underway, one very large piece of the virtual orientation puzzle was incomplete: staffing.

\section{Virtual Orientation Leaders}

One of the working teams was charged to develop a plan for how orientation leaders would serve new students through virtual orientation activities in June, July, and August 2020. The opportunity to meet and interact with current students is critical in providing a successful orientation and transition experience for new students. To serve students at each of the 20 undergraduate campuses, we determined that we needed additional student staff. Amid a hiring freeze, we submitted a proposal to the provost outlining our need to hire additional student staff from the Commonwealth campuses. Thankfully, the request was approved. We turned to our colleagues at the campuses to identify potential orientation leaders. Months earlier, we had identified staff from the flagship campus. In about 10 days, the team grew from 24 to 56 orientation leaders.

The leadership of the orientation leader working team met with the staff who supervise orientation leaders at each campus to identify potential staff. The greatest concern expressed in that meeting was whether campuses could still hire orientation leaders to work with new students during local Welcome Week programming. The working team saw the importance of that and worked to develop a funding proposal that would allow individual campuses to maintain their budget for orientation leader salaries. The Orientation Office funded the work of the virtual orientation leader team centrally. On May 14, we hosted an all-orientation leader staff meeting, which included 56 orientation leaders—about half of whom we have still not met in person.

\section{A "Familiar" Rhythm}

Though anything but ordinary, the cadence and rhythm of the orientation programming felt familiar from that point forward. Orientation leader training began on May 21. Ten days later, on June 1, we welcomed the first cohort of new students to virtual orientation. Over the weeks that followed, we offered 36 virtual orientation programs. We welcomed more than 17,000 new students and their families - working from the comfort of guest rooms, home offices, kitchen counters, and, when the weather was nice, outdoor living spaces.

The rhythm of orientation was familiar, but the daily experiences were anything but familiar (See Figure 1). We hosted 12 Day 1 sessions throughout the summer, welcoming, on average, 1,200 students at each event. Each Day 1 session consisted of three live-stream welcomes that were broadcast, quite literally, around the world. We traded in the technical service staff in the student union building for a producer, technical director, and teleprompter operator. One member of the team was broadcast live from the university's television studio and local PBS affiliate for each of these live streams. Orientation leaders led small groups from their homes up and down the East Coast, some even from the Midwest. The professional team in the Orientation Office helped 17,000 students through orientation, mostly via emails, phone calls, and the occasional text message.

[insert Figure 1 after this point] 


\section{Virtual Orientation Schedule \\ We expect students to complete orientation in 3-5 days}
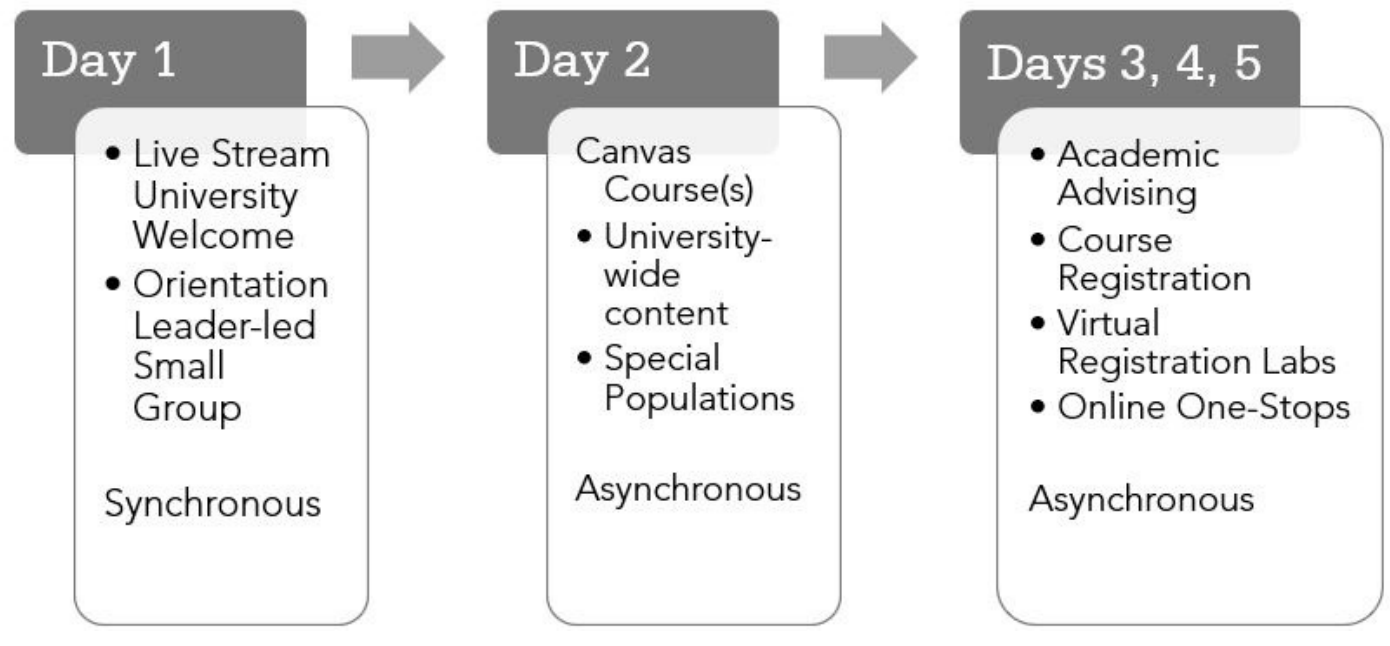

We relied on that rhythm of orientation in our work with colleagues around the university. Though the delivery methods were different, the processes associated with onboarding a new student were the same. A popular phrase in our work became, "The traditional traffic patterns are still in play."

The systems we used to facilitate orientation worked together, if by nothing other than force. Within the Orientation Office, we created a 24-step process (Step 13 had 12 sub-steps). The Director Team (four professional staff and one full-time student employee) managed the process while reminding staff from across the university what the processes were, who was doing and not doing what, and re-explaining the universitywide program calendar. Because a global pandemic was not enough to manage, 2020 brought us a summer of national unrest over systemic racism. Our students and orientation leaders who participated in and worked for NSO from their homes were experiencing protests in their front yards. During a protest that turned violent, an orientation leader's home was broken into. He still showed up to work with a smile the next morning.

In late July, our attention shifted to the next step in the orientation experience: Welcome Week. On July 31 , the university announced plans to keep the fall semester start date intact, which provided an additional challenge. We had to find a way to move students into their residence halls and fill in the gaps between the traditional two-day, overnight orientation and the 2020 virtual orientation program. We had spent the summer welcoming students to the university virtually. Now, we needed to shift our energy and attention to how we would welcome them in person amid a pandemic. Some decisions were easy. Traditional events like New Student Convocation presided over by the president would need to be offered virtually. Other decisions were more challenging.

\section{The Need for Extended Orientation}

An extended orientation was developed for the flagship campus because we believed it allowed us to introduce the physical campus and local community to new students more effectively. During virtual orientation, 
we introduced new students to the college experience. Still, those conversations were taking place on couches, in childhood bedrooms, and in many cases, a few feet away from a parent or family member. Those joining us on campus needed to reengage in orientation conversations, notably ones about alcohol and drug use; sexual assault prevention; and diversity, equity, and inclusion. With students arriving a week earlier than usual to help facilitate a safe and physically distanced move-in process, these topics became the core of extended orientation programming.

Our planning partners in housing and residence life determined that it would take about a week to move all students into their residence halls in a physically distanced manner. This schedule is very different from the usual arrival, spread out over three to four days. The plan was to have students participate in a required floor meeting with their resident assistant the evening they arrived on campus. On the following day, new students would participate in required extended orientation sessions built on the foundational messages delivered during virtual orientation. Throughout the week, new students received an introduction to the classroom environment (in-person, remote, and mixed-mode), had opportunities to practice navigating a physically distanced campus, and learned about life in the local community. We asked other departments on campus to offer supplemental extended orientation programs throughout arrival week as a way for students to learn about resources, navigate campus, and meet others.

Students were automatically assigned to extended orientation sessions based on their arrival date and received a detailed schedule of events once they arrived on campus. Since housing was not managing any early-arrival groups (e.g., outdoor orientation programs, marching band, honors students), we had a unique opportunity to create a shared experience for everyone. This approach assured that new students successfully fulfilled the required extended orientation programming before participating in any other programming scheduled to take place that week offered by their academic college, department, scholarship program, student organization, or community agency.

Welcome Week programming was offered throughout the week and coordinated by residence life, student activities, and the Orientation Office. These events included campus tours, networking opportunities, and featured performers or concerts. Each program had the goal of helping new students meet each other and develop connections. Most of these programs were offered virtually due to virus mitigation restrictions at the Commonwealth and university levels.

The week before the start of the fall semester is always a busy time for orientation and transition professionals. It is true that in our early COVID planning days, we talked about the importance of welcoming this incoming class with fireworks and marching bands when August finally arrived. Unfortunately, the virus had different plans for us. Fireworks and marching bands would have to wait.

Fall 2020 was unlike anything we had experienced before. We were charged with implementing and hosting the only in-person, on-campus experience for students via extended orientation. We also had to coordinate the entire campus community's effort to host an entirely virtual Welcome Week experience. Our entire team was performing orientation duties, serving as de facto public health ambassadors for the campus and testing the preparedness of our classrooms for physical distancing and mixed-mode learning.

We quickly learned that the campus was not ready to welcome all of us back. Attempts to assure physical distancing in the classrooms were not complete. Seats in many of the classrooms were supposed to be taped off to ensure that students would sit the required six feet apart—-they were not ready at the start of extended orientation. The university ordered about a half-million masks to distribute to students, staff, and faculty. The Orientation Team started work without those masks in hand. Across campus, we navigated entryways filled with empty hand-sanitizer dispensers. We served as a pilot for in-person learning during COVID. Because of our 
efforts, not only were new students better prepared to begin the semester, but the university was more prepared to receive them.

Monday, August 24, arrived. It was the weirdest first day of classes we had ever experienced. But we had done it. We had met Team F's charge. In five months, we shifted an entire orientation experience from an inperson program to a virtual experience, which we delivered university-wide. We welcomed students back to campus in person and did so while keeping students, the campus community, and ourselves healthy and safe.

\section{Lessons Learned}

It is not an understatement to say that 2020 changed us all - personally and professionally. If we miss the opportunity to make meaning of that experience, we miss critical opportunities to grow. We learned lessons we believe will strengthen us, our team, future programming, and the university.

One of the greatest professional growth opportunities came because of the regular feedback and criticisms we heard about the plan we were building. Late in the spring, but early in the virtual orientation cycle, we developed a set of guiding principles that would inform how we navigated the months ahead. We regularly had to remind ourselves:

1. Our plan is good. In a crisis, good now is better than perfect later.

2. Poor leadership or communication in other units is not our responsibility.

3. We are guided by good principles: keeping people safe, assuring equitable access, and following the science.

Though frustrating to us, the deliberate and delayed approach to announcing summer plans gave us time to pivot without the pressure of an open reservation system. Many other universities were not so lucky. We believe that the pressure to provide answers likely short-changed other schools' ability to troubleshoot and develop more creative solutions. It is okay and important to pause, evaluate options, and build a coalition in an age of instant information. Today's enrollment management landscape has often resulted in increasingly early access to orientation reservations to have students commit to orientation (and the institution) as soon as possible. Yet, we believe it is as important for institutions to create accurate expectations through the orientation experience as it is to yield a class. We can engage in the yield process in ways that do not involve an orientation reservation.

As far as we know, we were the only multi-campus institution that took a university-wide approach to implementing virtual orientation. We may also be the only multi-campus institution that approaches the day-to-day work in this collaborative manner. Collaboration has always been at the core of our work, and it is what saved us in 2020. For years, our director has said, "Orientation is the university's program; we are just the ones tasked with facilitating it." Never was this truer than in 2020. Not only were we able to engage the Student Orientation and Transition Network in the development and delivery of virtual orientation, but we also facilitated opportunities for the individual members of the working teams to establish, renew, or deepen their personal and professional networks throughout the university. The benefit of this approach is the opportunity it provides to strengthen the work we do in the future - around orientation and so much more.

The multi-campus approach provides an incredible opportunity to support student access and success. As a land grant university, we take great pride in our ability to serve the Commonwealth. The multi-campus approach is also challenging. We are often, and rightly, criticized for decisions made at the flagship campus and shared out to the other campuses. Certainly, some elements of the virtual orientation planning required a decision to be made centrally; however, the membership of Team F and the working teams meant that representatives from other campuses had a voice in those decisions. The engagement of dedicated campus staff made sure we avoided historical pitfalls or unintended consequences. 
We have heard that "in a crisis, the best thing you have is your credibility." In truth, the single greatest asset to us during the COVID-19 response was the years of effort we had invested before 2020 to building a collaborative university-wide network, maintaining strategic relationships, delivering on past promises, and being transparent in the development and delivery of in-person programs.

Communication is key. This is true in a typical planning year but was especially true in our pivot to virtual orientation. In a traditional year, the orientation staff work from several locations around campus. To accommodate this, the Orientation Office has always been early adopters of new technology that eases remote, asynchronous, team collaboration, combined with easy access to cloud file storage. In fact, in January of 2020, we had just completed an office-wide transition to the Office 365 environment - a move that, in hindsight, would be critical to our success in leading this effort. We used Microsoft Teams to organize various working teams, creating public channels to help with information sharing and using private channels to give teams space to workshop ideas before they were shared. We used SharePoint to post updates and distribute information to the university community. We hosted Zoom webinars (with more than 900 attendees) to talk through virtual orientation updates and answer questions.

Critical to our success in communicating with our partners was our willingness to acknowledge what we knew and did not know. Like many leaders, we try to minimize the appearance that we do not have answers to people's questions. We found success in framing each conversation in the following way:

- Here is what we know...

- Here is what we do not know...

- Here is what we are actively working on answering for you...

Looking back, it is safe to say that two early decisions contributed to our success. The decision to offer synchronous activities was critically important to student engagement and understanding of the orientation process. Students made a reservation for a three-hour block of time during which their Day 1 activities would take place, giving students dedicated time with the NSO Team - both professionals and orientation leaders. Together, we outlined the process for students, and they were able to leave feeling certain of their next steps.

The opportunity to meet with an orientation leader and an academic advisor in real-time, is resourceintensive - both in time and in money. If we believed it was worth the investment in the past, it became increasingly critical during the COVID-19 pandemic. We have known for a long time that orientation leaders are the bread and butter of our programs, and we knew that we needed them if we wanted to be successful in 2020. Orientation leaders provided critical connections for new students and helped them to feel engaged, even virtually.

We also have to acknowledge the limits of virtual programming. No matter how many fun and optional activities are offered, students are just "zoomed out." For example, we offered Virtual Registration labs several times per week; often, only one or two students dropped in during the two-hour session. Game nights were marginally more popular, yielding about two dozen students per session. Considering we hosted those in conjunction with Day 1 sessions, 24 students out of 1,200 is not a success. As we plan for virtual orientation in 2021, we will continue to offer these optional activities, but we will offer fewer of them.

Finally, we learned the importance of being a part of the solution. The entire university faced an unexpected and extraordinary challenge, and as a result, the staff were asked to move mountains and complete Herculean tasks to meet the mission. We quickly realized the importance of being a part of the solution rather than being a hurdle to one. We experience great collaborative efforts from staff on many campuses. Those partners embodied the true spirit of collaboration and demonstrated genuine care for students and their success. Unfortunately, others remained unmoved by the unprecedented moment in which we found ourselves. 
Stuck in old patterns and routines, slow to act, and all too eager to identify the faults in our plans and ideas, these partners made an already difficult situation nearly impossible. We are reminded of the importance of being a part of the solution-even an imperfect one-and encourage readers to remember what is possible when they set ego aside to search for solutions to shared challenges.

\section{Looking to the Future}

As eager as we may be to put the summer 2020 orientation cycle behind us, the impacts of that cycle will be felt for years to come. We believe that is as it should be.

We have been forced to develop new ways of thinking about how we share information with new students and those who support them, how we collaborate with programming partners, and how we use technology to bring it all together. Commitments to access and equity will all necessitate keeping elements of the virtual orientation programs moving forward. We are on the institutional front line, ensuring students have the tools, equipment, and access they need to succeed.

While there were many challenges to overcome in summer 2020, one stands out at the top of the list: the importance of a student's ID card signaling their membership in the university community. The summer of 2020 affirmed what many of us already know. The student ID is more than just transactional; it is also powerfully symbolic, helping students establish identity and sense of belonging and providing access to the benefits of the university. The ID card process was stretched during 2020. At the start of 2020, we had just begun discussions with the ID card office about implementing a mobile photo upload process for students. COVID catapulted that planning forward. A plan for mobile uploads was fast-tracked, but producing and distributing the cards to students at each campus was grueling.

About two weeks into the fall semester, students learning remotely started reporting that they still had not received their ID cards by mail. They felt left out. In many cases, they could not access proctored exams because a student ID card is needed for entry. This experience taught us not to underestimate the importance of tangible objects in a fast-moving and ever-evolving world. We must use the physical markers of membership, even in virtual programming.

We decided not to collect formal assessment data for the 2020 orientation cycle. This decision was partly informed by the belief that virtual orientation would be a one-off program offered the height of the pandemic. We also had to make decisions about how best to use our planning time. As we prepare for another summer of virtual orientation in 2021, we are renewing our efforts to assess and evaluate the student and family experience at orientation.

The fall semester offered opportunities for us to spend a considerable amount of time talking about the eventual return to in-person programming. In hindsight, having access to assessment and evaluation data from 2020 would be helpful. We currently rely on anecdotal data from the orientation leaders, academic advisors, new students, and staff in the Orientation Office to form plans for summer 2021. Many of our partners have acknowledged that being forced to go virtual expedited some early plans to move part of orientation content online. We anticipate that virtual elements will remain in the orientation program for years to come. We are eager to have important discussions about what we can continue to offer online and what should return to an inperson experience. We plan to ask new students this important question as part of the 2021 evaluation.

Our orientation programs cannot remain entirely online post-pandemic. If the fall semester had been anything close to normal, we believe our students would not have been fully prepared for the opportunities and challenges that presented themselves without experiencing our tested NSO curriculum. It is hard to replace meeting people in person, seeing the campus, learning to navigate the dining halls, and visiting campus officially 
for the first time as a student. Our university offers a storied residential learning experience, and the orientation program should support and mirror that experience.

If not evident earlier in this paper, the pivot to virtual orientation reinforced the critical partnerships between orientation planners and academic advisors. Through conversations in the fall and spring semesters since virtual orientation, we have begun to consider the possibility of decoupling academic advising conversations from the on-campus NSO program. Virtual orientation allowed us to offer individual advising meetings for each new admit for the first time. The benefit of the individual connection between student and advisor was felt early on. Advisers reported that students were reaching out via email for follow-up appointments or asking questions well before the start of the semester. Of course, the volume of students presents logistical and human resource challenges for continuing to offer individual advising meetings as part of an in-person program. We have begun to ask the question: What does orientation look like with a virtual advising appointment after an in-person visit?

These are all important questions for the future. As of this writing, that future continues to offer more questions than answers about the full-scale return to in-person on-campus experiences and the lasting lessons we will take away from the past year. Those are all things we don't know. What we do know is that we are proud to have leveraged a university-wide network of 20 residential campuses throughout the Commonwealth and the online world campus to support students as they began their degrees during a global pandemic. We will continue to have new opportunities to support these students as they transition between and among the campuses in the years ahead. We will continue to bridge systems, expand our coalition of partners, and center students and their success in our efforts. 


\section{Appendix A: Team F Charge}

Group Charge:

Acclimate and orient new first-year, transfer, and graduate students to the university (NSO/ISO/TSO, graduate orientation, etc.). This team will ensure continuity between admission to the university and enrollment through a series of deliberate engagements and communications with students.

Key Areas of Focus:

- Develop a coordinated series of messages to students and families to keep students and families engaged with the university, reinforcing our commitment to students until they can begin classes

- Develop remote or online orientation modules and information for all campuses and student types

- Communicate options and guidance to students with an eye toward flexibility

- Ensure all students have access to university systems needed to engage with the university

- Share materials and plans with professional schools (e.g., law schools, medical schools) 


\section{Appendix B: Virtual Orientation Working Teams}

Each part of the virtual orientation plan required heavy lifting by the university. To accomplish this, the group charged with providing leadership for acclimating and orienting new students to the university (Team F) served as both an action team for ongoing COVID-19 response activities as well as the steering group for a set of university-wide working teams to accomplish our goal to deliver a high-quality onboarding experience.

Integration (Team F)

- Participate, as able, in Wednesday morning COVID-19 enrollment management calls

- Coordinate efforts of other COVID-19 response teams as it relates to onboarding

- Develop a timeline for the work of various Team F working teams

Advising

- Provide regular updates to the University Advisory Council and NSO planners in each college

- Coordinate summer advising efforts with the ongoing work of COVID-19 Response Team C

- Develop a consistent set of expectations/guidance for one-on-one advising appointments

- Provide structure to how campuses/colleges could staff advisors for orientation

- What role, if any, could peer advisers play in this model?

Change of Campus (COC)

- How will we support students anticipating a campus change not in the position to do so now?

- Identify change of campus students to serve as resource or connection for current students

- Collect information from each campus about what services or programs are available for COC

- Review and enhance change of campus website resources

\section{Communications}

- Who will tell students what to do and when?

- Develop a plan to keep parents/family members engaged throughout the summer

- Develop social media strategy to engage students throughout the summer

- Coordinate communication efforts with COVID-19 Enrollment Teams I \& J

- Coordinate assessment strategy for orientation related activities

- Develop shared and consistent orientation messaging for campuses/colleges

Content

- Use the content grid to determine university-wide content to be included in welcome/modules

- Develop specific content for students, parents \& family members, campuses, and colleges

- What tools will be needed to collect content from university partners? (e.g., Auburn template)

- Are there ways in which robots can virtually connect with resources/campus tours?

\section{International Student Orientation}

- Identify considerations related to onboarding international students across the university

- Work to ensure the needs of international students are maintained in this new model

- Attend to the specific documentation and process needs of international students

- Develop a framework for ongoing engagement post-advising and pre-Welcome Week

- Collaborate with Welcome Week working team to develop intentional opportunities for integration, community building, and cross-cultural engagement opportunities

\section{Orientation Leaders}

- Identify contact list of orientation leader supervisors to encourage information sharing 
- Verify and gather additional information about the current state of orientation leader hiring at campuses

- Gather a list of roles/expectations for orientation leaders

- What role, if any, will volunteer orientation leaders play in this orientation framework (Welcome Week?)

- Develop a framework for how orientation leaders will interact with new students in this model Registration

- Explore and advocate for effective course enrollment management strategies

- Determine what information needs to be shared with campus registrars

- Develop tools to help academic advisors become familiar with the student experience in the course planning guide

\section{Special Populations}

- Identify and collect a list of special population considerations across the university

- Work to ensure the needs of special populations are maintained in this new model

- Balance the needs between campus-wide shared experiences and program-specific needs

- Develop a framework for ongoing engagement post-advising and pre-Welcome Week

Systems and Schedule

- How should events in VZO be developed to have students make their orientation reservations?

- What role will a guest reservation play in this model? What does it trigger, give access to?

- Assure that we can provide access to Canvas before/at matriculation

- How will students transition from VZO to Starfish?

- What role could a Starfish Success Plan play in tracking students through orientation?

- When or how will orientation holds be removed/replaced? Is a second hold necessary for recordkeeping?

- What mechanism should we develop to check in at the start of the semester? (confirm arrival)

- Explore the possibility of using an optional event module (VZO) for Welcome Week

- The timeline should be developed to allow sufficient time for students starting in Summer Session

Welcome Week (WW)

- Provide WW guidance for residential and non-residential campuses (committees)

- Coordinate summer advising efforts with the ongoing work of COVID-19 Response Team G

- Explore how we might incorporate NSO Resource Fairs into WW (separate from involvement)

- Discuss the impact on campus convocations and college dean's meetings

- Collect contact information for convocation coordinators, and communicate regularly

- Develop a system for collaboratively managing space reservations/facilities to meet all needs

- Help balance the needs between campus-wide shared experiences and program-specific events

- Determine programming time required for robust WW and estimate need for earlier arrival date 